\title{
Simulação do escoamento de grãos de soja em um secador com fluxo contínuo
}

\author{
Rodolfo França de Lima Saul Vione Winik* \\ Vanessa Faoro Manuel Osório Binelo Oleg Khatchatourian \\ Departamento de Ciências Exatas e Engenharia da Universidade do Noroeste Regional, Rio Grande \\ do Sul, R. São Francisco, 501, 98700-000, Ijuí, RS, Brasil \\ E-mail: rodolfofrancadelima@gmail.com,saul.winik@gmail.com,vanefaoro@yahoo.com.br \\ Manuel.binelo@gmail.com,olegkha@unijui.edu.br.
}

Pesquisas sobre transferência de calor e massa possuem um vasto acervo na literatura. Com a intenção de averiguar mais detalhadamente o fluxo de grãos, neste trabalho será realizado um estudo do escoamento de grãos de soja em secadores de fluxo misto que segundo [6] são amplamente utilizados na agricultura em todo o mundo, porém ainda existe uma necessidade de aperfeiçoar este tipo de equipamento. Conhecer o fluxo dos grãos é fundamental em uma rede armazenadora, pois sua irregularidade pode produzir uma secagem não uniforme do grão, e em alguns casos, aumentar o risco de incêndio no interior do secador. Para a criação de modelos matemáticos de secagem mais precisos, deve-se considerar os campos de velocidade do ar durante o processo e os campos de velocidade da massa de grãos. Pesquisas recentes estão sendo realizadas para a análise do escoamento de materiais granulares em silos e secadores de grãos. Pesquisadores como [8], [6], [1], [2], [4], tem se dedicado a estudar a modelagem do fluxo de grãos, através de simulações numéricas.

Entre as técnicas de simulação estudadas está o Método dos Elementos Discretos (MED). O MED é um método de simulação numérica do movimento de um grande número de partículas dentro de um sistema fixo ou móvel variante no tempo. Foi desenvolvido por [3], sendo baseado em um esquema numérico explícito no qual a interação das partículas é monitorada individualmente. Em cada contato o sistema é modelado usando as leis do movimento, representando o meio como um conjunto de partículas independentes, interagindo umas com as outras, reproduzindo explicitamente a natureza discreta de um meio granular [7], [8]. Foi implementado no software livre Yade, um código que realiza a simulação do escoamento de grãos de soja com fluxo de descarga contínuo. Foi adotada uma geometria similar à de [6] de um secador de fluxo misto equipado com dispositivos de descarga conforme a Figura 1. Para a simulação foram utilizadas partículas esféricas, cuja suas propriedades podem ser observadas na Tabela 1 e o modelo de contato utilizado foi o linear.

\begin{tabular}{|c|c|}
\hline $\begin{array}{c}\text { Figura 1: Simulação do escoamento dos } \\
\text { grãos de soja. }\end{array}$ & $\begin{array}{c}\text { Figura 2: Gráfico do escoamento dos grãos de } \\
\text { soja selecionados. }\end{array}$ \\
\hline
\end{tabular}

Tabela 1: Parâmetros de entrada para modelagem MED.

\begin{tabular}{ccc} 
Variavel & Soja & Unidade \\
\hline Densidade & 1243 & $\mathrm{~kg} / \mathrm{m}^{3}$ \\
Coeficiente de Poisson & 0.25 & - \\
Módulo de Young & $2.6 \mathrm{E}+06$ & $\mathrm{~Pa}$ \\
Angulo de Atrito & 0.4712 & Radianos \\
Coeficiente de atrito de rolamento das particulas & 0.05 & - \\
Coeficiente de amortecimento & 0.05 & - \\
Raio médio das particulas & 3.08 & $\mathrm{Mm}$ \\
Desvio padrão & 0.2730 & $\mathrm{Mm}$ \\
Passo de tempo da simulação & $3.8 \mathrm{E}+06$ & \\
\hline
\end{tabular}

Foi monitorada a trajetória de quatro partículas vermelhas durante o escoamento. Essas foram escolhidas a partir do eixo $\mathrm{x}$ da geometria criada da seguinte maneira: a primeira partícula que estava exatamente no centro do eixo, a segunda que estava afastada $50 \mathrm{~mm}$ do centro, uma terceira a $100 \mathrm{~mm}$ e uma quarta partícula que estava a $150 \mathrm{~mm}$ do centro (encostada na parede

* Bolsista de Iniciação Científica PIBIC/CNPq 
da geometria). As posições verticais das partículas selecionadas durante a simulação são apresentadas na Figura 2. O primeiro grão a chegar até a base da geometria foi o segundo grão mencionado anteriormente mantendo-se em velocidade quase que constante durante sua trajetória, isso se deve ao fato que esta partícula se moveu com baixo efeito de atrito, pois não tocou na parede lateral e não foi obstruído pela calha central. Após a chegada deste primeiro grão analisado a simulação foi finalizada. O segundo grão a chegar mais próximo da saída do secador foi o terceiro grão selecionado inicialmente, pela sua curva exposta na Figura 2 é possível verificar que até o primeiro segundo de descarga ele teve um escoamento lento em relação aos três seguintes, isso pode ser atribuído ao fato que mesmo não estando junto a parede, o grão permanecia em uma região próxima, sofrendo assim os efeitos do atrito, também se deve levar em consideração que esse grão passou muito próximo a calha, região onde existe alto atrito. $\mathrm{O}$ terceiro grão a chegar à mais próximo dos orifícios de descarga foi a partícula que estava situada junto a parede lateral da geometria. Na Figura 2 é possível verificar que este grão manteve-se com velocidade baixa durante todo o tempo de simulação, isso aconteceu porque este grão ficou muito próximo a parede, sofrendo o efeito do atrito com a parede. $\mathrm{O}$ último grão que foi analisado foi aquele que estava exatamente no centro da geometria.

De acordo com a simulação realizada conclui-se que em secadores de fluxo misto os grãos têm diferentes velocidades verticais, resultando em diferentes tempos de residência da massa de grãos, concordando com [5] que em seus experimentos de transporte de material a granel, mostrou o grande efeito do atrito com a parede e com os obstáculos do duto de ar. Fato este que pode resultar em uma secagem não uniforme da massa de grãos e risco de incêndio do secador, ocasionado pelos grãos que ficariam tempo excessivo sob a ação do ar quente. Se pode concluir ainda que o atrito dos grãos com as paredes e calhas representa um fator de grande influência para a não homogeneidade do padrão do fluxo da massa de grãos.

Palavras-chave: Método dos Elementos Discretos (MED), Fluxo de Grãos, Parâmetros Iniciais

\section{Referências}

[1] Boac, J. M., Casada, M. E., Machirang, R. G., III, J. P. H. 3d and quasi-2d discrete element modeling of grain commingling in a bucket elevator boot system. Transactions of the American Society of Agricultural and Biological Engineers, (2012) 55, 659 - 672.

[2] Coetzee, C., Els, D. The numerical modelling of excavator bucket filling. Journal of Terramechanics. (2009) 46 (5), 217-227

[3] Cindall, P. A., \& Strack, O. D. L. Discrete numerical model for granular assemblies. International Journal of Rock Mechanics and Mining Sciences and Geomechanics. Abstracts Geotechnique, (1979) 16, 77.

[4] Goda, T. J., Ebert, F. Three-dimensional discrete element simulations in hoppers and silos. Powder Technology, (2005) 158, 58-68.

[5] Keppler, Istvan. Kocsis, Laszlo. Oldal, Istvan. Farkas, Istvan. Csatar, Attila. Grain velocity distribution in a mixed flow dryer. Advanced Powder Technology, (2011) 23 (2012) 824-832.

[6] Mellmann, J., Iroba, K., Metzger, T., Tsotsas, E., Mszros, C., Farkas, I. Moisture content and residence time distributions in mixed-flow grain dryers. Biosystems Engineering, (2011) 109, 297 - 307.

[7] Mesquita, A., Silva, M. O., Santos, E, Carvalho, L.C., Gomes, E., Neto, E., Mafra, M. Uso do método dos elementos discretos em manuseio de minérios e sua contribuição para a pós graduação e graduação no curso de engenharia mecânica da UFPA. Anais: XL Congresso Brasileiro de Educação em Engenharia - COBENGE, Belém, PA, Brasil. (2012).

[8] Montellano, C. Ramirez, Á. Gallego, E. Ayuga, F. Validation and experimental calibration of 3D discrete element models for the simulation of the discharge flow in silos. Chemical Engineering Science, 66, Issue 21, (2011) 5116-5126. 